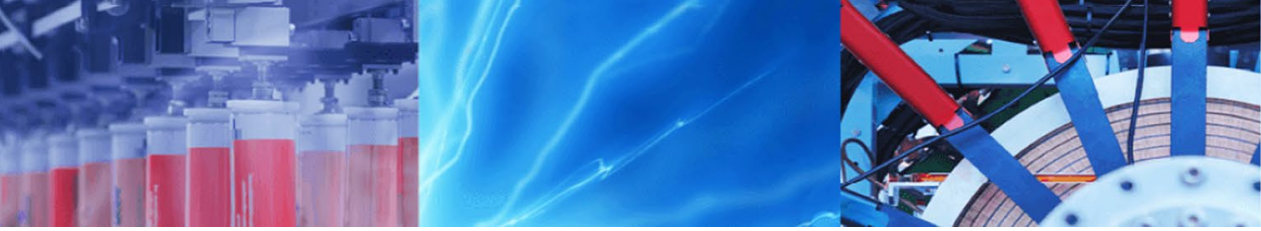

Research Article

\title{
Sustained larger-amplitude self-oscillations induced by the BZ reaction involving $\mathrm{Fe}(\text { phen })_{3}$ catalyst
}

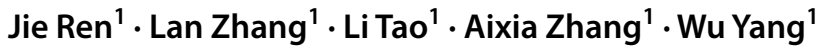

(c) Springer Nature Switzerland AG 2019

\begin{abstract}
The poly(VP-co-AA-co-CD-co-Fe(phen) ${ }_{3}$ ) self-oscillating polymer gels composed of 5-acrylamide-1,10-phenanthroline bis(1,10-phenanthroline) iron(II) (Fe(phen) $)_{3}$, vinyl-pyrrolidone (VP), beta-cyclodextrin ( $\beta$-CD) and acrylic acid (AA) were synthesized by radical polymerization. The volume, color and the redox potential self-oscillations were observed synchronizing with chemical wave propagation in acid-free conditions. The amplitude of diameter oscillation was about $40 \mu \mathrm{m}$ to approximately $10 \%$ of its initial diameter and that of the redox potential about $125 \mathrm{mV}$ at the optimal conditions. Moreover, the oscillation could sustain several hours. The long-lasting oscillation gels with large amplitude under mild conditions will be useful for the development of biomimetic materials that can undergo self-oscillation without external stimuli in mild conditions.
\end{abstract}

Keywords Self-oscillating gels $\cdot$ Poly $\left(\mathrm{VP}-\mathrm{co}-\mathrm{AA}-\mathrm{co}-\mathrm{CD}-\mathrm{co}-\mathrm{Fe}(\mathrm{phen})_{3}\right)$ polymer $\cdot \mathrm{BZ}$ oscillating chemical reaction

\section{Introduction}

The first self-oscillating polymeric materials based on the Belousov-Zhabtinsky (BZ) reaction was reported in 1996 [1]. It composed of poly( $\mathrm{N}$-isopropylacrylamide) (PNIPAAm) and $\mathrm{Ru}(\mathrm{bpy})_{3}$ which acts as the metal catalyst for the $B Z$ reaction. The $B Z$ reaction, a well-known oscillatory chemical reaction accompanies a rhythmical oscillation of the redox potential of a metal catalyst and spatial patterns. Up to now, it is the most extensively studied oscillating chemical reaction $[2,3]$. The self-oscillation and chemical wave observed in the BZ reaction has been discovered in living systems, such as glycolytic oscillations, biorhythms, heart muscle tachycardia, self-organization of ameba cells and intracellular calcium concentrations. In addition, the BZ reaction also provided a chemical and physical model for understanding several autonomous phenomena observed in biological systems $[4,5]$. The driving force for self-oscillating of the BZ gels is provided by the changing of the redox potential of metal catalyst in the BZ reaction.
When the gels which copolymerized functional monomer with $\mathrm{Ru}(\mathrm{bpy})_{3}$ is immersed into the $\mathrm{BZ}$ system free of a metal catalyst, the copolymerized $\mathrm{Ru}(\mathrm{bpy})_{3}$ acts as the metal catalyst as in the classical BZ system and the reaction occurs inside the gels. Therefore, a periodical oscillation of the redox potential for $\mathrm{Ru}(\mathrm{bpy})_{3}$ moiety generates due to the change from the oxidized state to the reduced state periodically. Due to the hydrophilicity of the polymer chain increasing with $\mathrm{Ru}(\mathrm{bpy})_{3}$ in the oxidized state for more positive charges and decreasing in the reduced state, the change in redox states of the polymerized catalyst moiety affects the hydrophilicity of the network and induces the changes in the volume phase transition temperature of the gel as well as the swelling ratio. As a result, the gel exhibits an autonomous volume oscillation with the redox oscillation in the closed solution under constant conditions.

To date, great progress has been made in self-oscillating materials and a variety of polymeric materials have been studied for bioengineering and engineering applications

$\triangle$ Jie Ren, jieren@nwnu.edu.cn | ${ }^{1}$ Chemistry and Chemical Engineering College, Northwest Normal University, Key Lab of Polymer Materials of Ministry of Education of Ecological Environment, Lanzhou 730070, People's Republic of China. 
[6-8]. A new kind of self-oscillating gel actuator which exhibited various behaviors of peristaltic motions without external stimuli was demonstrated. The content of each component in the polymer network were gradient distribution and which led to a successive self-walking motion like a looper in the BZ system under constant temperature [9]. The walking velocity of the gel was approximately $170 \mu \mathrm{m} / \mathrm{min}$ and it could be controlled by the concentration of substrates in the BZ solution. A pendulum motion of the gel also was observed by fixing one edge [10]. A periodic reciprocating motion was obtained when the Rucatalyst in the gel was rapidly oxidized and slowly reduced [11]. In addition, an object could be transported autonomously by utilizing the peristaltic motion and chemical wave propagation coupling with the diffusion of intermediates in the gels [12-14]. In fact, the self-oscillating gel has been investigated as an unprecedented biomimetic material in the past 10 years [15-18]. Other works related to the oscillating chemical reactions coupling with polymers were performed. Pojman et al. demonstrated that oscillating chemical reactions might couple to polymerization processes by exploiting the oscillatory production of malony radicals in the cerium catalyzed $B Z$ system $[19,20]$. Also, theoretical and computational approaches were used to simulate the motions of the gels and provide the necessary guidelines for assembling the components into the appropriate pattern to yield the specified function [21, 22].

More recently, there were many excellent works related to self-oscillating gels providing novel concepts of biomimetic materials. For example, an autonomous functional surface composed of a self-oscillating polymer brush [23], an autonomous cycling artificial vesicles with synthetic block copolymers formation and fragmentation self-oscillating [24], a cross-linked polymersomes exhibiting self-beating motion like biological cell membranes without any external stimuli to trigger on-off switching [25] and an artificial cells by synthetic materials [26] were demonstrated. These self-oscillating polymer gels are expected to apply as novel biomimetic materials in a number of aspects including auto-mobile actuators and beating micropumps. Moreover, these achievements are also very important from the perspective of understanding the universal rhythms phenomena that sustain life and occur at all levels in physiological tissue.

Several works involving the volume oscillations of selfoscillating gels also were performed. However, the amplitudes aren't satisfactory. Arimura et al. [27] obtained the poly(NIPAAm-CO- $\mathrm{Fe}\left(\right.$ phen) ${ }_{3}$ ) gel exhibiting 7\% swelling/ deswelling variation in the gel length. The amplitude of diameter oscillation poly(VP-Co-AA-co-Fe(phen) ${ }_{3}$ ) gels was about $20 \mu \mathrm{m}$ to approximately $5 \%$ of its initial diameter [28]. In this study, we tried to construct a novel selfoscillating gel with biocompatible monomers. Therefore, vinyl-pyrrolidone (VP), beta-cyclodextrin $(\beta-C D)$, acrylic acid (AA), and 5-acrylamide-1,10-phenanthroline bis(1,10phenanthroline) iron(II) $\left(\mathrm{Fe}(\text { phen })_{3}\right)$ were used to prepare the crosslinked gel. Except for the unique biologic properties, the $\beta-C D$ segments efficiently regulate the diffusion rate of the $B Z$ substrates. And the AA segments can control the swelling process and provide $\mathrm{H}^{+}$for the $\mathrm{BZ}$ reaction. The influence of the immobilized $\beta-C D$ content on the period and the amplitude of the self-oscillation were investigated. The results indicated that the amplitude of both redox potential and volume oscillations were larger than the reported self-oscillating gels. Therefore, the longlasting oscillation gels with large amplitude under mild conditions will be useful for the development of biomimetic materials.

\section{Experimental}

\subsection{Materials}

Vinylpyrrolidone (VP) and acrylic acid (AA) were brought from Tianjin Damao Chemical Reagent Factory and used after purification. $\beta$-Cyclodextrin $(\beta-C D)$ was used as received. The cross-linker $\mathrm{N}, \mathrm{N}$-methylene bis-acrylamide (MBA) and the initiator ammonium persulfate (APS) were brought from Shanghai Zhongqin Chemical Reagent Ltd. Malonic acid (MA), $\mathrm{KBrO}_{3}, \mathrm{H}_{2} \mathrm{SO}_{4}, \mathrm{Ce}_{2}\left(\mathrm{SO}_{4}\right)_{3}, \mathrm{Ce}\left(\mathrm{SO}_{4}\right)_{2}$ and 1,10-phenanthroline were analytical reagents and used as received. 5 -acrylamide-1,10-phenanthroline bis $(1,10$ phenanthroline) iron(II) (Fe(phen) $)_{3}$ ) was synthesized by ourselves. The distilled water was used throughout the experiments.

\subsection{Preparation of poly(VP-co-AA-co-CD-co-Fe(phen) $)_{3}$ ) gel}

The self-oscillating gels (the chemical structure as shown in Fig. 1) with different contents of $\beta-C D$ were synthesized as following: $0.025 \mathrm{~g}$ sample of $\mathrm{Fe}(\text { phen })_{3}$ was dissolved in $6.0 \mathrm{~mL}$ of distilled water and mixed with $4.0 \mathrm{~mL}$ of $A A$ solution and $9.0 \mathrm{~mL}$ of solution containing $0.7 \mathrm{~g} \mathrm{VP}$ and a certain quality of $\beta-C D$ as shown in Table 1 . The mixture was stirred for $20 \mathrm{~min}$, then the mixture consisting of $0.01 \mathrm{~g} \mathrm{APS}$ and $0.01 \mathrm{~g} \mathrm{MBA}$ was added. The copolymerization reaction occurred at $60^{\circ} \mathrm{C}$ for $6 \mathrm{~h}$ under $\mathrm{N}_{2}$ bubbling. A cylindrical poly(VP-co-AA-co-CD-co-Fe(phen) $)_{3}$ ) gel was prepared by injecting the pre-gel solution into glass capillaries (inner diameter: $0.5 \mathrm{~mm}$ ) and removed the glass capillaries by hydrofluoric acid treatment. The obtained gels were immersed in distilled water for a week by daily change water. 


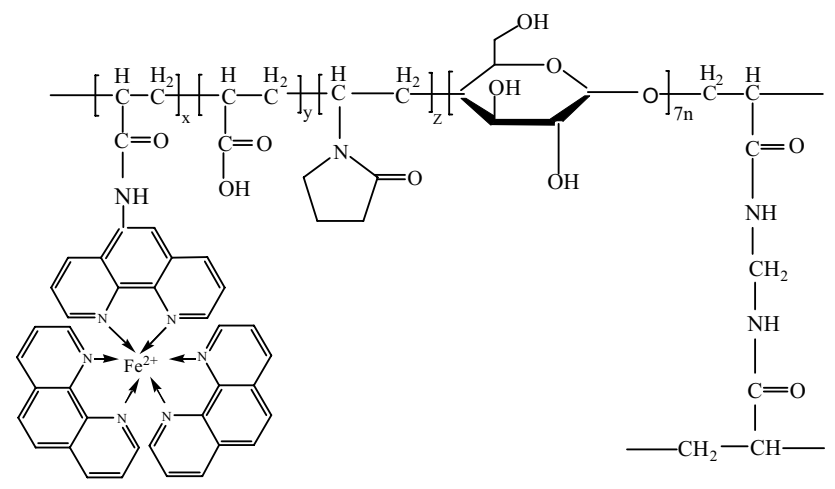

Fig. 1 The chemical structure of the self-oscillating gel

\subsection{Characterization}

SEM micrograph: The gels were freeze-dried before covered with a conductive coating. The SEM micrograph was obtained on a JSM-6701F scanning electron microscope(JEOL, Japan) and the surface morphology was observed at $20 \mathrm{kV}$.

Equilibrium swelling measurement: The equilibrium swelling ratio of gels in distilled water, the reduced state, and the oxidized state were investigated and $0.01 \mathrm{~mol} \mathrm{~L}^{-1}$ $\mathrm{Ce}\left(\mathrm{SO}_{4}\right)_{2}\left(\mathrm{I}=1.0 \mathrm{~mol} \mathrm{~L}^{-1}\right)$ and $\mathrm{Ce}_{2}\left(\mathrm{SO}_{4}\right)_{3} \mathrm{~L}^{-1}\left(\mathrm{I}=1.0 \mathrm{~mol} \mathrm{~L}^{-1}\right)$ solutions were used as the oxidizing and reducing agents, respectively. A block of dry gel was immersed in the above-mentioned media for $24 \mathrm{~h}$, taken out and weighted after the remaining solution on the surface was absorbed. The swelling ratio of the samples was calculated using the following formula:

$\mathrm{SR}=\left(\mathrm{W}_{\mathrm{t}}-\mathrm{W}_{\mathrm{d}} / \mathrm{W}_{\mathrm{d}}\right)$

where $S R$ is the swelling ratio, $W_{t}$ and $W_{d}$ are the quality of the gel in swelling equilibrium and dry gel, respectively.

Volume self-oscillation measurement: A cylindrical poly(VP-co-AA-co-CD-co-Fe(phen) ${ }_{3}$ ) gel was put on a slide and a drop of $B Z$ solution (containing $0.50 \mathrm{~mol} \mathrm{~L}^{-1} \mathrm{MA}$ and $0.15 \mathrm{~mol} \mathrm{~L}^{-1} \mathrm{KBrO}_{3}$ ) was added to observe the volume and color self-oscillation and the chemical wave propagation. Time-lapse imaging at room temperature was recorded on a stereomicroscope (Olympus, BX53).

Potential self-oscillation measurement: The experiments were performed in a glass reactor (ca. $50 \mathrm{ml}$ ) coupled with an SY-601 thermostat and a Model ML-902 magnetic stirrer. The prepared gels were cut into cuboid (length: $30 \mathrm{~mm}$, width: $20 \mathrm{~mm}$, thickness: $2 \mathrm{~mm}$ ) and immersed in $\mathrm{BZ}$ system as described above at $20^{\circ} \mathrm{C}$. A $\mathrm{CHI}-832$ electrochemistry analyzer (Shanghai Chenhua Instrument Company, China) was connected directly to the reactor through a Pt-electrode (Rex, 213, China) as the working electrode and an $\mathrm{Hg}_{2} \mathrm{SO}_{4}$ reference electrode to record the potential change.

\section{Results and discussion}

\subsection{SEM images analysis}

Figure 2 shows the SEM images of the prepared selfoscillating gels. It is found that the gels exhibit pore structure just like honeycomb and the pore diameter is smaller than that of the poly(VP-co-AA-co-Fe(phen) ${ }_{3}$ ) gel [28]. Moreover, the pore diameter decreases with the increasing of $\beta-C D$ content. This is closely related to the molecule structure of $\beta-C D$ with a truncated cone structure having hydrophobic inner cavities and hydrophilic outer surface [29].

\subsection{Equilibrium swelling ratio}

The equilibrium swelling ratios of the prepared gels in distilled water, $0.01 \mathrm{~mol} \mathrm{~L}^{-1} \mathrm{Ce}_{2}\left(\mathrm{SO}_{4}\right)_{3}$ solution $\left(\mathrm{I}=1.0 \mathrm{~mol} \mathrm{~L}^{-1}\right)$ and $0.01 \mathrm{~mol} \mathrm{~L}^{-1} \mathrm{Ce}\left(\mathrm{SO}_{4}\right)_{2}$ solution $\left(\mathrm{I}=1.0 \mathrm{~mol} \mathrm{~L}^{-1}\right)$ are shown in Table 2 . The swelling ratios in distilled water are much greater than which in $\mathrm{Ce}_{2}\left(\mathrm{SO}_{4}\right)_{3}$ and $\mathrm{Ce}\left(\mathrm{SO}_{4}\right)_{2}$ solutions for the effect of ionic strength. In addition, the swelling ratios for the $\mathrm{Fe}(\text { phen })_{3}$ moiety in the oxidation state are greater than which in the reduction state. The reason may be lying in the more positive charge in the oxidation state making the hydrophilicity of the gel chain being stronger than which in the reduction state [30]. It can also be found that the swelling ratios decrease with the increasing of $\beta-C D$ content. Due to the large molecule structure of $\beta-C D$, the holes become smaller with the increasing of $\beta-C D$ content (as shown in Fig. $2 d$ ), and the swelling ratios decrease correspondingly.
Table 1 The amounts of reactants in each prepared gel

\begin{tabular}{lllllll}
\hline Samples & Fe(phen) $)_{3}(\mathrm{~g})$ & $\mathrm{AA}(\mathrm{mL})$ & $\beta-\mathrm{CD}(\mathrm{g})$ & $\mathrm{VP}(\mathrm{g})$ & $\mathrm{APS}(\mathrm{g})$ & $\mathrm{MBA}(\mathrm{g})$ \\
\hline $\mathrm{G} 1$ & 0.025 & 4.000 & 0.025 & 0.700 & 0.010 & 0.010 \\
G2 & 0.025 & 4.000 & 0.050 & 0.700 & 0.010 & 0.010 \\
G3 & 0.025 & 4.000 & 0.100 & 0.700 & 0.010 & 0.010 \\
G4 & 0.025 & 4.000 & 0.200 & 0.700 & 0.010 & 0.010 \\
\hline
\end{tabular}



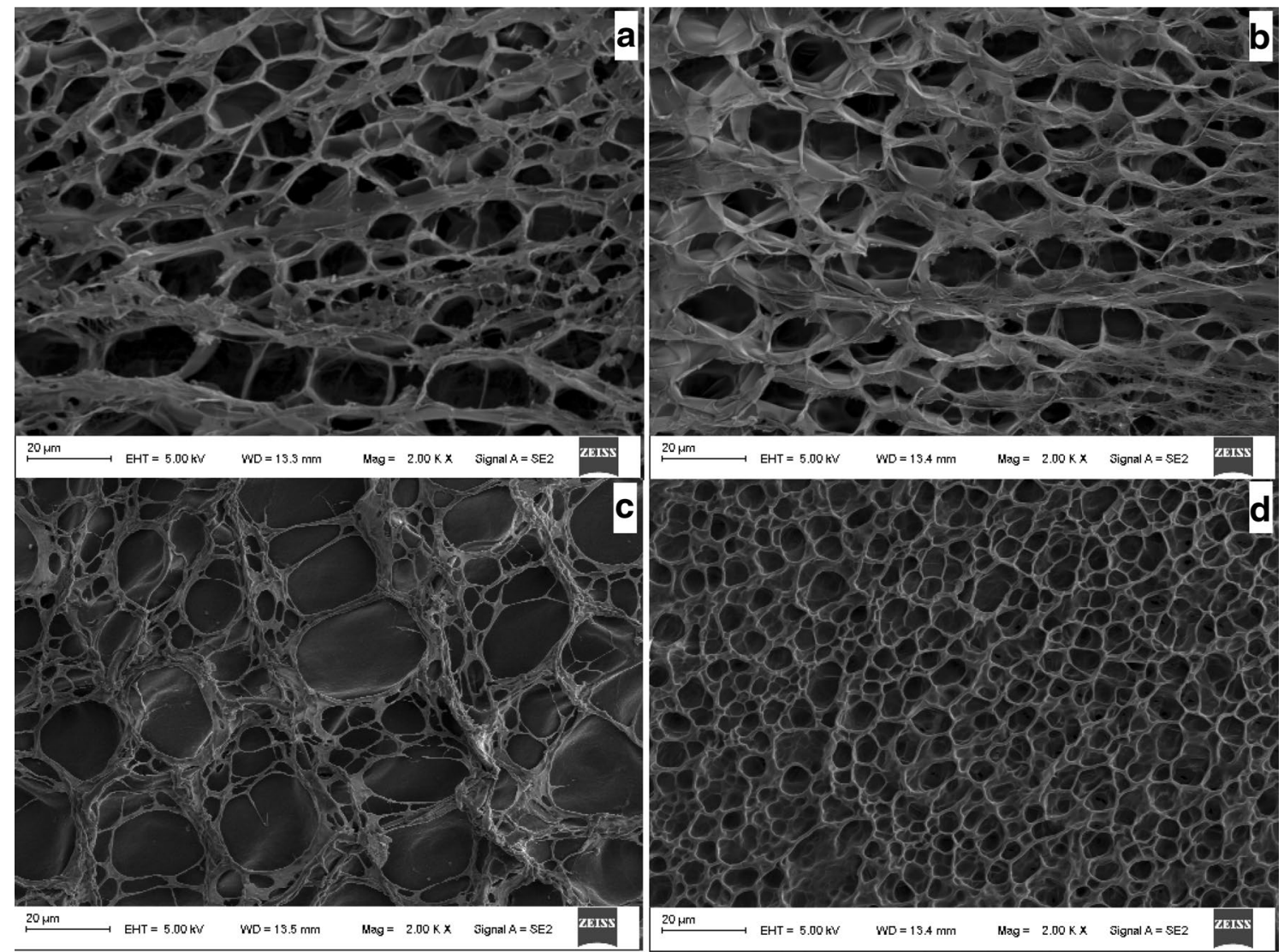

Fig. 2 The SEM images of the prepared gels (a G1; b G2; c G3; d G4)

Table 2 The equilibrium swelling ratio for the gels in different solutions

\begin{tabular}{llll}
\hline Samples & $\mathrm{H}_{2} \mathrm{O}$ & $\mathrm{Ce}(\mathrm{III})$ & $\mathrm{Ce}(\mathrm{IV})$ \\
\hline $\mathrm{G} 1$ & 512.89 & 7.03 & 9.66 \\
$\mathrm{G} 2$ & 283.17 & 6.51 & 8.74 \\
$\mathrm{G} 3$ & 229.28 & 6.42 & 8.45 \\
$\mathrm{G} 4$ & 133.69 & 6.18 & 6.84 \\
\hline
\end{tabular}

\subsection{Self-oscillating behavior}

Figure 3 shows the redox potential self-oscillating behavior of the prepared gels in the BZ aqueous solution free of catalyst and acid. The figures on the left are the redox potential as the function of time and the enlarged figures in the red rectangle are on the right. It can be seen that a long-lasting and larger amplitude self-oscillating polymer under mild conditions was obtained. The $\mathrm{G} 1 \mathrm{gel}$ can oscillate continuously more than $5 \mathrm{~h}$. The long-lasting oscillation gel with large amplitude under mild conditions is beneficial for development of biomimetic materials that can undergo self-oscillation without external stimuli. According to the mechanism of the classical BZ reaction
[3], the bromination and oxidation reactions of organic species by acidified bromate in the presence of a metal catalyst accompanied by a periodical change of catalyst in the oxidation and reduction states. The catalyst is necessary to observe the oscillating phenomenon when MA is used as the organic species. Therefore, the redox potential oscillating observed in Fig. 3 demonstrated that the $\mathrm{Fe}(\text { phen })_{3}$ moiety copolymerized in the gels could catalyze the $\mathrm{BZ}$ reaction as $\mathrm{Ce}^{4+} / \mathrm{Ce}^{3+}$ couple. Moreover, due to different copolymerized $\beta-C D$ content and different threedimensional network structure of the prepared gels, the oscillation period and amplitude are different. Maybe the reason lies in the different diffusion rate of the $B Z$ solution in the gels.

In contrast, the equilibrium swelling ratios of the prepared gels decrease drastically with the increasing of $\beta-C D$ content. Moreover, the differences between the oxidation state and the reduction state also decrease. The $\mathrm{G} 2$ was selected to observe the volume self-oscillation and chemical wave propagation. Figure 4 shows successive profiles of the cylindrical poly(VP-co-AA-co$\mathrm{CD}-\mathrm{co}-\mathrm{Fe}(\text { phen })_{3}$ ) gel volume and color self-oscillating phenomenon under constant temperature. When the prepared gel was immersed in the BZ solution free of

\section{SN Applied Sciences}



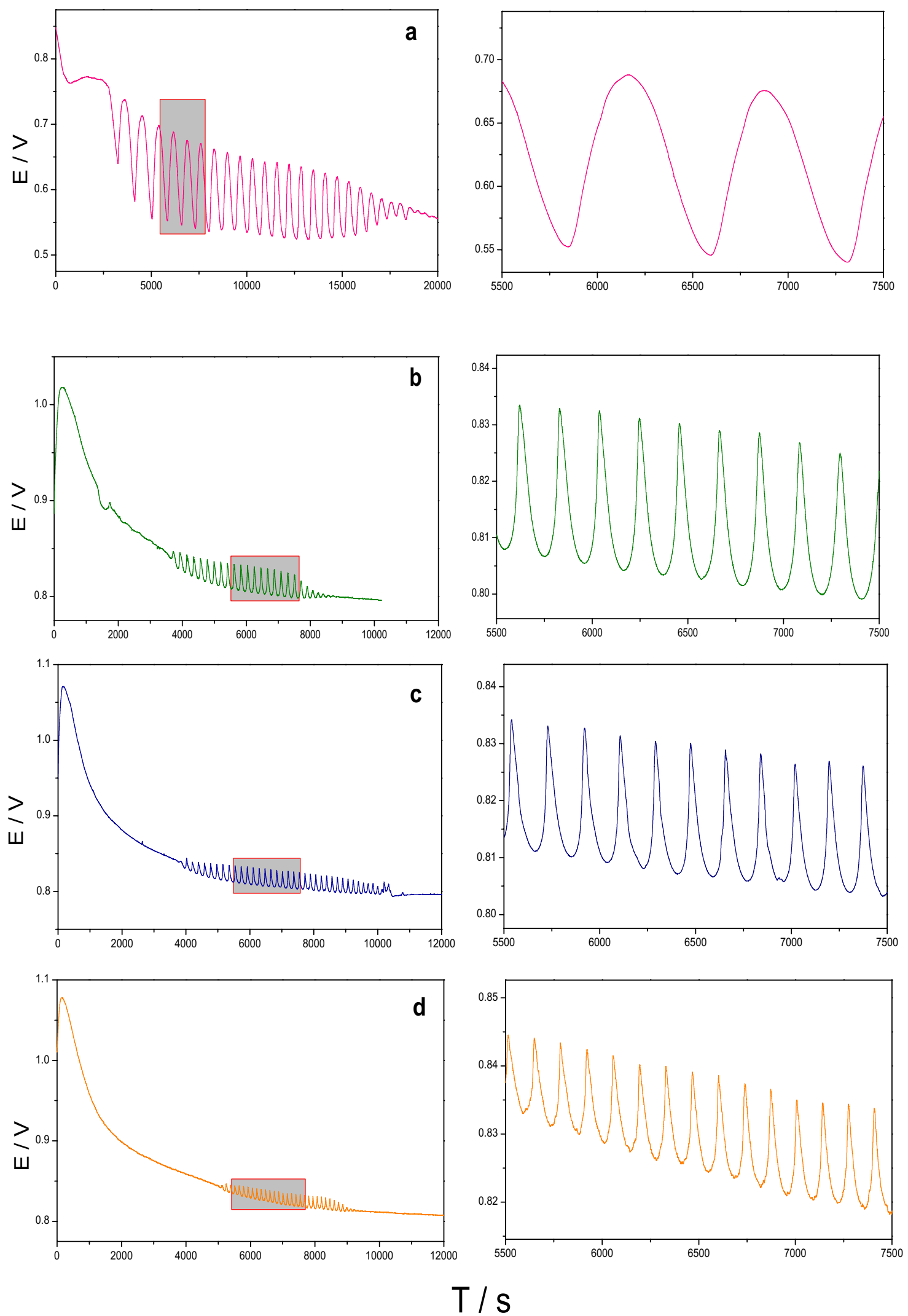

Fig. 3 Typical oscillation waveform of the redox potential of gels in the BZ system (a G1, b G2, c G3, d G4). Common conditions: $[\mathrm{MA}]_{0}=0.50 \mathrm{~mol} / \mathrm{L},\left[\mathrm{KBrO}_{3}\right]_{0}=0.15 \mathrm{~mol} / \mathrm{L}$, temperature: $20^{\circ} \mathrm{C}$ 


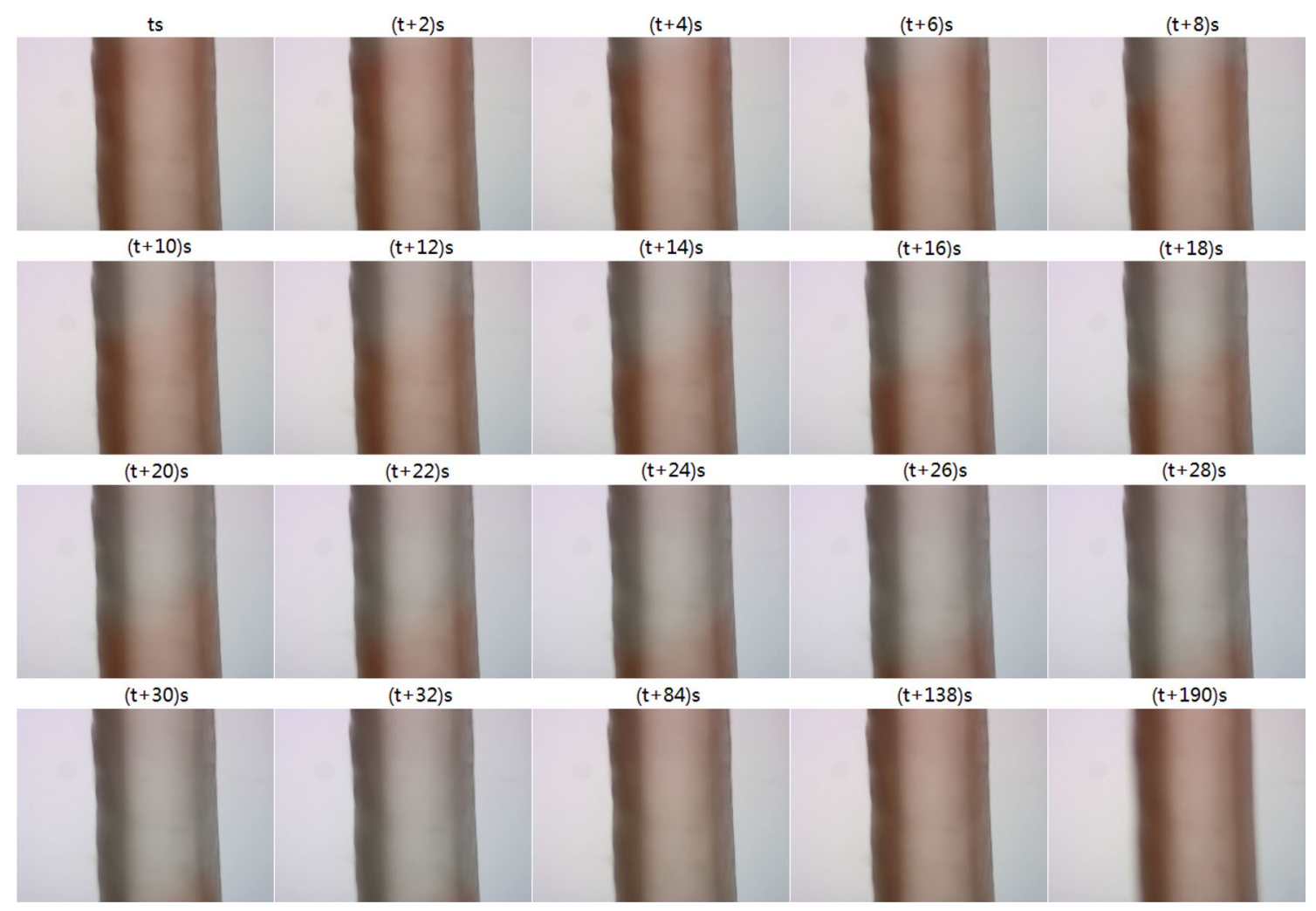

Fig. 4 Time course of chemical wave propagation in poly(VP-co-AA-co-CD-co-Fe(phen) $\left.{ }_{3}\right)$ gel in the BZ solution containing $0.3 \mathrm{~mol} \mathrm{L^{-1 }} \mathrm{MA}$ and $0.1 \mathrm{~mol} \mathrm{~L}^{-1} \mathrm{KBrO}_{3}$ at $20^{\circ} \mathrm{C}$

catalyst and acid, the redox potential self-oscillation was observed. The result indicated that the immobilized $\mathrm{Fe}(\text { phen })_{3}$ in the gel did act as the catalyst of the $\mathrm{BZ}$ reaction just as $\mathrm{Ru}(\mathrm{bpy})_{3}$ moiety. Also, the copolymerized $A A$ could provide $\mathrm{H}^{+}$which is necessary for the $B Z$ reaction. Therefore, the $B Z$ chemical oscillating reaction occurs inside the gels and $\mathrm{Fe}(\text { phen })_{3}$ moiety is oxidized by the intermediates and reduced periodically. Due to the hydrophilicity of $\mathrm{Fe}(\text { phen) })_{3}$ moiety being larger in the oxidized state than in the reduced state, the volume of the gel changes periodically synchronizing with the color changing between red and light blue. Moreover, the chemical wave generates and propagates in cylindrical poly(VP-co-AA-co-CD-co-Fe(phen) ${ }_{3}$ ) gel. In the gel, the amplitude of diameter oscillation is about $40 \mu \mathrm{m}$ to approximately $10 \%$ of its initial diameter. The period of volume oscillation is approximately $200 \mathrm{~s}$ as shown in Fig. 5, which is in good agreement with the redox potential oscillation. The chemical wave propagation velocity is approximately $50 \mu \mathrm{m} / \mathrm{s}$. In addition, the oxidized and reduced states gels in the process of self-oscillation are shown in Fig. 6. It can be seen that the amplitude is much larger than poly(VP-co-AA-co-Fe(phen) ${ }_{3}$ ) gel [28]. This is identical with the results in Table 2. However, in the oxidized and reduced states, the diameter differences of

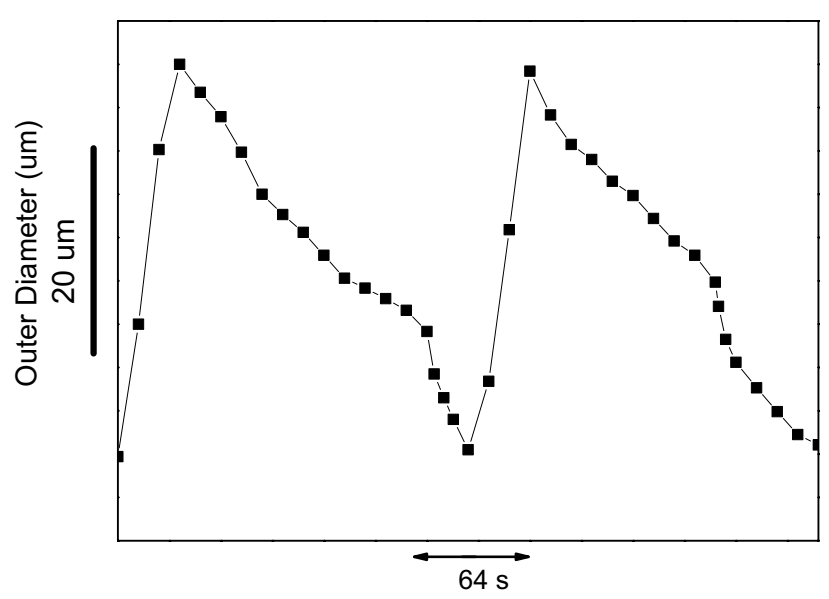

Fig. 5 Profiles of swelling/deswelling oscillation for the poly(VP-coAA-co-CD-co-Fe(phen) $)_{3}$ ) gel at $20^{\circ} \mathrm{C}$

the gels in the $\mathrm{BZ}$ solution are smaller than which in the $\mathrm{Ce}_{2}\left(\mathrm{SO}_{4}\right)_{3}$ and $\mathrm{Ce}\left(\mathrm{SO}_{4}\right)_{2}$ solutions. This is due to the gels reaching the equilibrium swelling state in the $\mathrm{Ce}_{2}\left(\mathrm{SO}_{4}\right)_{3}$ and $\mathrm{Ce}\left(\mathrm{SO}_{4}\right)_{2}$ solutions whereas there is not enough time to reach equilibrium swelling state and the gels have been oxidized or reduced by the BZ intermediates in the BZ system. 


\section{Oxidized state}

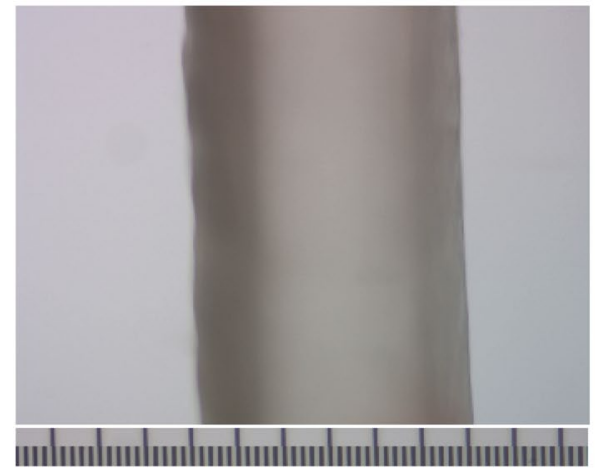

Reduced state

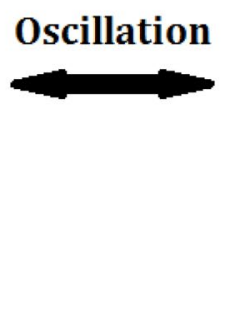

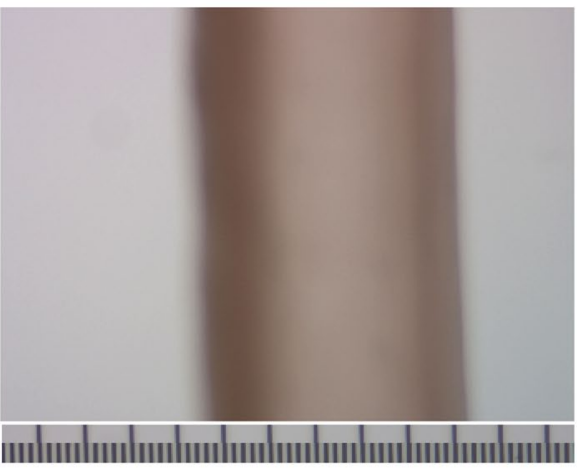

Fig. 6 Images of the cylindrical poly(VP-co-AA-co-CD-co-Fe(phen) $)_{3}$ ) gel in oxidized and reduced states in the BZ solution

\section{Conclusion}

In conclusion, a novel BZ type self-oscillating gels poly(VP-co-AA-co-CD-co-Fe(phen) $)_{3}$ ) was prepared successfully with $\mathrm{Fe}$ (phen) ${ }_{3}$ as the catalyst of the $\mathrm{BZ}$ reaction. The volume, color, and the redox potential selfoscillation were observed synchronizing with chemical wave propagation in acid-free conditions. The amplitude of diameter oscillation was about $40 \mu \mathrm{m}$ to approximately $10 \%$ of its initial diameter and that of the redox potential about $125 \mathrm{mV}$ at the optimal conditions and the oscillation could sustain several hours. Therefore, this self-oscillation gels would have wider application prospect as a novel biomimetic materials and further studies on control of oscillating behavior as well as practical applications are expected.

Acknowledgements This work was supported in part by the Basic Project of Science and Research of Colleges and Universities of Gansu Province (5001-109), the Project for Young Teacher of Northwest Normal University (NWNU-LKQN-13-6).

\section{Compliance with ethical standards}

Conflict of interest On behalf of all authors, the corresponding author states that there is no conflict of interest.

\section{References}

1. Yoshida R, Takahashi T, Yamaguchi T, Ichijo H (1996) Self-oscillating gel. J Am Chem Soc 118:5134-5135

2. Noszticzius Z, Bódiss J (1979) A heterogeneous chemical oscillator. The Belousov-Zhabotinskii-type reaction of oxalic acid. J Am Chem Soc 101:3177-3182

3. Field RJ, Körös E, Noyes RM (1972) Oscillations in chemical systems. Il. Thorough analysis of temporal oscillation in the bromate-cerium-malonic acid system. J Am Chem Soc 94:8649-8664
4. Dano S, Sorensen PG, Hynne F (1999) Sustained oscillations in living cells. Nature 402:320-322

5. Siegert F, Weijer C (1989) Digital image processing of optical density wave propagation in Dictyostelium discoideum and analysis of the effects of caffeine and ammonia. J Cell Sci 93:325-335

6. Zhou HW, Liang EX, Pan Y, Ding XB, Zheng ZH, Peng YX (2013) Self-tunable thermosensitive behavior by reorganizable architecture variation in the Belousov-Zhabotinsky reaction. RSC Adv 3:2182-2185

7. Ueki T, Yoshida R (2014) Recent aspects of self-oscillating polymeric materials: designing self-oscillating polymers coupled with supramolecular chemistry and ionic liquid science. Phys Chem Chem Phys 16:10388-10397

8. Zhou HW, Zheng ZH, Wang QG, Xu GH, Li J, Ding XB (2015) A modular approach to self-oscillating polymer systems driven by the Belousov-Zhabotinsky reaction. RSC Adv 5:13555-13569

9. Maeda S, Hara Y, Sakai T, Yoshida R, Hashimoto S (2007) Selfwalking gel. Adv Mater 19:3480-3484

10. Maeda S, Hara Y, Yoshida R, Hashimoto S (2008) Control of the dynamic motion of a gel actuator driven by the BelousovZhabotinsky reaction. Macromol Rapid Commun 29:401-405

11. Nakata S, Yoshii M, Suzuki S, Yoshida R (2014) Periodic reciprocating motion of a polymer gel on an aqueous phase synchronized with the Belousov-Zhabotinsky reaction. Langmuir 30:517-521

12. Tabata O, Hirasawa H, Aoki S, Yoshida R, Kokufuta E (2002) Ciliary motion actuator using self-oscillating gel. Sens Actuators $A$ 95:234-238

13. Yoshida R, Sakai T, Tambata O, Yamaguchi T (2002) Design of novel biomimetic polymer gels with self-oscillating function. Sci Technol Adv Mater 3:95-102

14. Tateyama S, Shibuta Y, Yoshida R (2008) Direction control of chemical wave propagation in self-oscillating gel array. J Phys Chem B 112:1777-1782

15. Murase Y, Takeshima R, Yoshida R (2011) Self-driven gel conveyer: effect of interactions between loaded cargo and selfoscillating gel surface. Macromol Biosci 11:1713-1721

16. Murase Y, Maeda S, Hashimoto S, Yoshida R (2009) Design of a mass transport surface utilizing peristaltic motion of a selfoscillating gel. Langmuir 25:483-489

17. Shiraki Y, Akimoto AM, Miyata T, Yoshida R (2014) Autonomous pulsatile flow by peristaltic motion of tubular self-oscillating gels. Chem Mater 26:5441-5443

18. Shiraki Y, Yoshida R (2012) Autonomous intestine-like motion of tubular self-oscillating gel. Angew Chem 124:6112-6116 
19. Pojman JA, Leard DC, West W (1992) Periodic polymerization of acrylonitrile in the cerium-catalyzed Belousov-Zhabotinskii reaction. J Am Chem Soc 114:8298-8299

20. Washington RP, West WW, Misra GP, Pojman JA (1999) Polymerization coupled to oscillating reactions: (1) a mechanistic investigation of acrylonitrile polymerization in the Belousov-Zhabotinsky reaction in a batch reactor. J Am Chem Soc 121:7373-7380

21. Yashin VV, Balazs AC (2006) Modeling polymer gels exhibiting self-oscillations due to the Belousov-Zhabotinsky reaction. Macromolecules 39:2024-2026

22. Yashin VV, Kuksenok O, Balazs AC (2010) Modeling autonomously oscillating chemo-responsive gels. Prog Polym Sci 35:155-173

23. Masuda T, Hidaka M, Murase Y, Akimoto AM, Nagase K, OkanoT, Yoshida R (2013) Self-oscillating polymer brushes. Angew Chem 52:7468-7471

24. Tamate R, Ueki T, Shibayama M, Yoshida R (2014) Self-oscillating vesicles: spontaneous cyclic structural changes of synthetic diblock copolymers. Angew Chem 53:11248-11252

25. Tamate R, Ueki T, Yoshida R (2015) Self-beating artificial cells: design of cross-linked polymersomes showing self-oscillating motion. Adv Mater 27:837-842
26. Tamate R, Ueki T, Yoshida R (2016) Evolved colloidosomes undergoing cell-like autonomous shape oscillations with buckling. Angew Chem 55:5179-5183

27. Arimura T, Mukai M (2014) A self-oscillating gel actuator driven by ferroin. Chem Commun 50:5861-5863

28. Ren J, Tao L, He JH, Zhang AX, Yang W (2018) Synchronous volume and color self-oscillating gels based on chemomechanical coupling. J Polym Res 25:25. https://doi.org/10.1007/s1096 5-017-1366-5

29. Gidwani B, Vyas A (2014) Synthesis, characterization and application of epichlorohydrin- $\beta$-cyclodextrin polymer. Colloids Surf $B$ Biointerfaces 114:130-137

30. Yoshida R, Sakai T, Ito S, Yamaguchi T (2002) Self-oscillation of polymer chains with rhythmical soluble-insoluble changes. J Am Chem Soc 124:8095-8098

Publisher's Note Springer Nature remains neutral with regard to jurisdictional claims in published maps and institutional affiliations. 